\title{
SLEEP IN CHILDREN AND ITS DISTURBANCES
}

\author{
AUGUST STRAUCH, M.D. \\ CHICAGO \\ REMARKS ON PHYSIOLOGY OF SLEEP
}

Czerny ${ }^{1}$ in his investigations of the sleep of children examined its depth and intensity under physiologic conditions; he used, as stimulus, the opening induction current, with increasing intensity, until awakening occurred. He demonstrated that the depth of sleep in healthy children depends on the period of sleep.

In very young nurslings after satiation sleep reaches its greatest intensity within the first hour, whereupon a very slow decrease ensues; after an average duration of sleep of three hours awakening takes place for the purpose of feeding. In older infants this sleep lasts somewhat longer. In two infants, 9 months old, the curve of the intensity of sleep (Fig. 1) during the whole night, demonstrates in Czerny's experiments two parts, separated from each other by a short waking interval, the maximum of depth of the second period being much less than that of the first period. The waking interval is due to the increasing desire for food, and, indeed, the former is absent, when, with the growing age of the children, the hunger stimulus becomes less and no more suffices to awaken them.

In six children between 2 and 6 years of age, who used to stay awake the whole day and slept throughout the night, the depth of sleep attained its maximum within the first hour, decreased during the second hour rapidly (Fig. 2), later more slowly, reaching its minimum in the fifth or sixth hour, and increased a second time in the morning. This second ascent of the curve, occurring in the ninth or tenth hour, however, did not reach the maximum of the first hour. This character of the curve suggests two periods of sleep by a continuous combination of the two foregoing night curves illustrated in Figure 1.

Similar experiments, it seems, have so far not been undertaken in older children, but it is assumed that their night curves may more and more approach those found in adult life, by Kohlschütter, Moenningshoff and Piesbergen, and recently by Michelson. Moenningshoff and Piesbergen determined the depth and intensity of sleep by finding the threshold value of an auditory stimulus necessary to wake the person at different intervals after he fell asleep. They found the attached

1. Czerny: Jahrb. f. Kinderh. 33:1. 
curve (Fig. 3), which is self-explanatory, the abscissae representing the duration of sleep, the ordinates the intensity of the stimulus necessary to awake.

Michelson's very exact investigations revealed two types of curves, representative of the depth of sleep in the adult. In the first type (Fig. 4) the sleep becomes rather rapidly profound, reaches its maximum in about the first hour and becomes in a short time shallow, maintaining after a few hours only a moderate degree of depth. With the representatives of the second type (Fig. 5) the sleep deepens slowly, obtains its maximum depth, that is less than in the previous type, not until after one to three hours; it then becomes shallow more slowly than in the first type, and remains even in the fifth and sixth hours rather deep.

These two sleep qualities seem to have a relationship to certain practical facts of life. The first curve is characteristic of those persons who retire early in the evening, fall asleep rapidly and profoundly and awake early in the morning, when they feel completely refreshed and efficient. The second curve (Fig. 5), the "morning type," concerns individuals who retire late, remain until late in the evening efficient, in possession of full, at least sufficient, freshness, but who in the morning require abundant sleep, rise reluctantly and obtain comparatively late their full capacity.

Psychologic experiments testing the mental capacity after normal and shortened sleeping hours, as undertaken by Roemer, ${ }^{2}$ reveal interesting data in relation to this subject. They indicate that after awakening, the maximum efficiency is generally obtained only gradually, particularly so by the "morning sleepers." In comparison with their efficiency after a normal duration of sleep, they do not show any decrease of it if they retire later in the evening, since the thus shortened sleep deepens correspondingly in compensation; but their efficiency is very markedly impaired and a state of fatigue results if they are aroused in the morning earlier than they are wont to awake. Evidently, shortening of the morning sleep means to them a considerable loss, since their demand for sleep is then still a great one, as expressed in the depth of the curve toward morning. Individuals of the first type, the "evening sleepers," whose maximum profundity of sleep is obtained rapidly, possess a certain superiority. Shortening of their sleep at evening influences likewise only a little their efficiency the next morning, since the thus curtailed sleep will mostly deepen compensatorily. Still less is their efficiency diminished by shortening the morning sleep, as their requirement of sleep is in the main already satisfied after from three to four hours.

2. Roemer: Congr. internat. de psychol., München., 1896, p. 354. 
These experiments have great importance in the hygiene of school children, inefficiency and fatigue being especially to be noticed after shortening of the morning sleep in children who obtain the maximum of their sleep (Roemer) in the morning. Aschaffenburg ${ }^{3}$ observed in some children even as young as in the second and third year of life an obvious tendency to go to rest late in the evening, evidencing then only little tiredness; they would awake late in the morning reluctantlty and with difficulty, sleeping then deeply in spite of the beginning day noises, while other children would rise very early and be lively. In a number of instances I have met with this type. This behavior is not necessarily the effect of education and environment, since both types occur in one and the same family. That in children the demand for sleep in the morning is a greater one than in the adult is indicated by

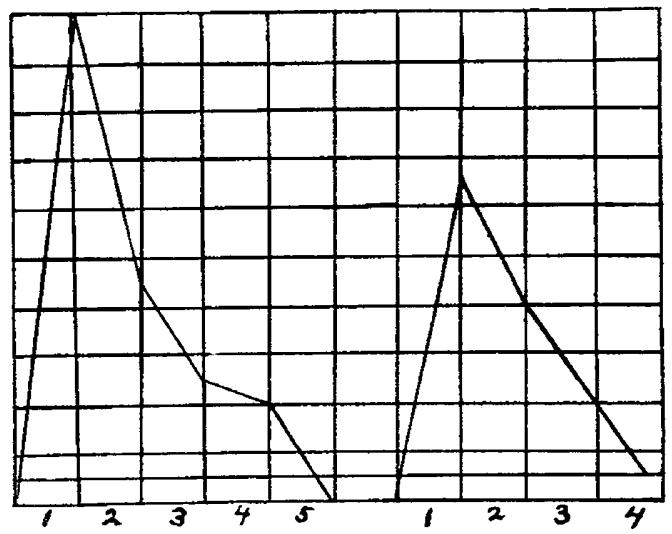

Fig. 1.-Curve of depth of sleep in a baby 9 months old (Czerny).

Czerny's curves. The majority of nervous children, but not infrequently also not nervous children, of school age represent in regard to their sleep requirement the "morning type." Their much reduced efficiency in the morning hours was repeatedly demonstrated by psychologic investigations, measuring the degree of fatigue, and it is the experience of many teachers that particularly nervous pupils are among those who achieve the least in the first hours of the forenoon instruction.

The dotted line in Figure 5 represents the depth of sleep during the darker nights of winter. It would indicate the great importance of darkness of the bedroom and is in keeping with the experience that people who sleep lightly will sleep more deeply and better if the room is completely darkened, whereas many of us will slumber only super-

3. Aschaffenburg: Verhandl. d. Gesellsch. f. Kinderh., 1908, p. 260. 
ficially or wake early in the summer, the dawning light acting as a powerful stimulus. We do not know what changes take place in the types as a result of pathologic conditions or change of environment, since experiments have not yet been made; neither can it be stated what other types and transitional forms there exist. Sleep in its physiologic and pathologic phenomena offers abundant interesting problems for experimental investigation and clinical observation in the directions indicated.

CLASSIFICATION OF DISTURBANCES OF SLEEP

Sleep disturbances may be classified from various points of view considering the variety of causes, the pathogenesis, the symptomatology, their relation to other disturbances, etc., and in the presence of the various combinations no classification can be enirely adequate, but bears more or less an arbitrary character. Sleep disturbances may be elementary, concerning the depth and duration, or they may manifest more complicated features and accompanying phenomena; they may be temporary or chronic; due to exogenic factors; or symptomatic, secondary to other diseases; or they may be idiopathic, that is, to a certain extent independent of any exogenic or organic detectable disturbances.

Sleep disturbances accompanying organic diseases. - It would require the presentation of the entire pathology of childhood should one attempt to enumerate all the possible common and uncommon diseases that may directly provoke disturbance of sleep. The latter may often be seemingly the only solitary symptom, whose underlying cause may not be suspected by the inexperienced. Painful conditions must be mentioned first. These dolorous forms of sleep disturbance, or restless sleep, where pain of any origin hinders normal sleep, may be brought about by numerous entirely heterogeneous affections. A most common cause are colic pains, distress and discomfort in gastrointestinal disorders; even slight nutritional disturbances cause babies to sleep poorly; likewise hunger as a result of a sudden diminution of the wonted amount of food, whilst in chronic underfeeding babies rather often will become accustomed to the small quantities; itching and irritating or painful skin lesions, as eczema, urticaria, strophulus, intertrigo and furuncles, the latter especially if exposed to pressure during sleep. Where sleep-disturbed nights precede the outbreak of urticaria, as I have observed, it is probably due to the at first latent digestive disturbance that underlies both conditions. It is important to keep in mind that otitis media in the child-especially to be considered during epidemics of grip - may evidence itself by no other symptom than moderate fever and sleeplessness, resulting from pain which is not localized by the infant, and thus easily overlooked. That 
fever itself with its increased temperature and the accompanying processes may cause sleeplessness as a symptom of the involvement of the nervous system is evident from the sleep-producing effect of antipyresis, be it through drugs or hydrotherapy.

Respiratory obstructions and difficulties, as those due to stenosis of the upper air passages in acute or chronic rhinitis, in adenoids, pseudocroup, dyspnea due to bronchial asthma or cardiac lesions will naturally render the sleep very restless and interrupted; they may cause awakening, starting with gasping for air and feeling of suffocation, or more complicated disturbances, as pavor nocturnus. In one of my observations a severe nocturnal attack of suffocation that frightened the patient and family was traced to penetration into the

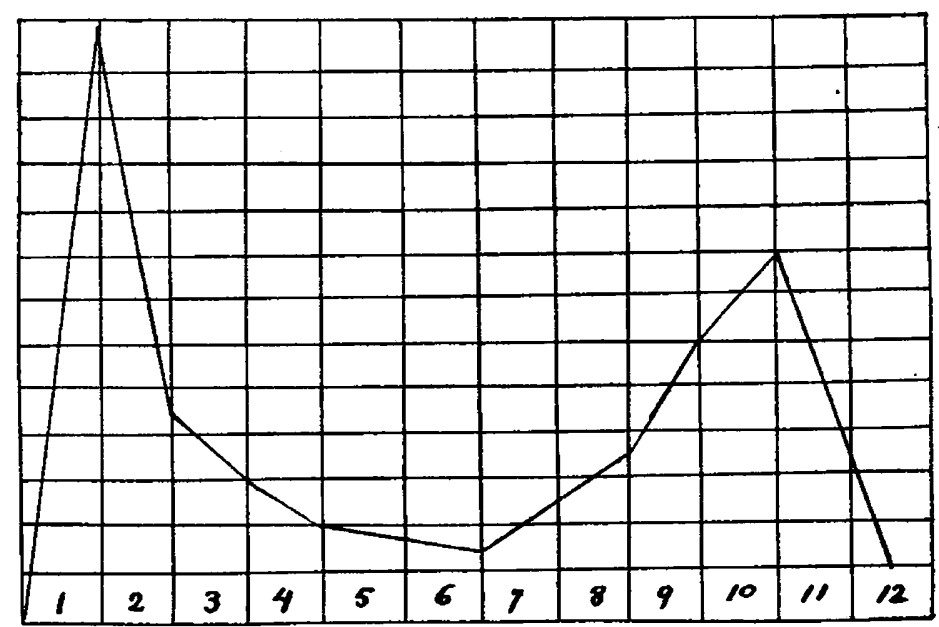

Fig. 2.-Curve of intensity of sleep in a child 3 years and 8 months old (Czerny).

larynx, with resulting severe laryngospasm, of regurgitated hyperacid stomach contents during profound sleep after a heavy supper.

Among the chronic ailments, anemia and rhachitis, especially with craniotabes, will cause restless sleep as a nervous symptom, yielding to a certain extent to phosphorus and cod liver oil. The motor irritation phenomena of chorea minor, tetanus, tetany and athetosis may directly interfere with healthy sleep, as also pollakiuria and polyuria; if the latter symptom be due to partaking of great quantities of liquid before or at bedtime, the abolishment of this habit will within a short time remedy the disturbance.

Extraneous causes, educational factors.-Among the extraneous causes of troubled sleep, namely, those existing in the surroundings, brief mention may be made of a few that are often overlooked by the 
attendants and therefore must be pointed out by the physician; deficient ventilation, lack of comfort, lack of quiet and darkness, faulty temperature of the room, with overheating or cooling of the body, exposure of feet in a cold room, lying wet. Too low temperature, insufficient covering will, especially in the morning hours, disturb sleep, as they act as awakening stimuli. The depth of sleep in infants depends on retention of warmth. According to Czerny's observations, infants do not sleep well if they do not come into a state of perspiration and warmth, and his investigations demonstrated that the maximum (perspiration) and minimum of moisture and warmth of skin coincide with the maximum and minimum depth of sleep, respectively. The importance of ventilation, so evident in its beneficial effect on sleep in children who are allowed to sleep on the porch, is not realized by the immigrant from Europe, though among them the ventilation would seem the more imperative, as not infrequently several persons occupy the same bedroom. Discomfort of the resting place comprises also the sleeping in the same bed of several persons, though habit has a mitigating influence.

Unfavorable crowded home conditions of the poor cause the younger children to be habitually deprived night after night of their full quota of sleep by the late retirement of the older persons of the family. Physicians, educators and school workers have repeatedly pointed out that the health and efficiency, especially of children of school age, are injured through such exogenic factors. Occasionally overburdening in school work, too much mental exertion, perverted distribution of the day hours, premature and untimely participation in social affairs and pleasures of the adult, abuse of alcohol, tea, coffee and tobacco, and even sexual stimuli, which later shall be discussed, home work and home industry until late hours, will, by habitually curtailing the minimum sleep requirement, exert a very detrimental effect on the young. Such children soon suffer in their general state of health; the appetite decreases, they often have headache, the mucous membranes lose their healthy hue; skin, muscles and panniculus adiposus become flabby and the youthful, frolicking nature with its love for work is replaced by inattention, fatigue and reduced efficiency in school work; finally, they become nervous and suffer from insomnia, establishing thus a vicious circle.

Idiopathic sleep disturbances.-Idiopathic sleep disturbances are likewise either temporary or chronic, the latter through their great importance being here the subject of closer discussion. Their clinical manifestations are of manifold character; they may be limited to the period of falling asleep, or may continue into the sleep proper, or may concern the latter only. 
Stereotypias.-As is well known, children often have the habit of falling asleep in a certain fashion; as, for instance, with their playthings, a favorite toy animal or a doll at their side, or with the corner of the bed clothes or one or more fingers in the mouth; some will, as I have seen, suck the finger only when falling asleep, though not at other times, this being apparently an agreeable sleep promoting stimulus. A nervous girl, 5 years old, for two years had the habit of pulling and twisting the hair over her right temple regularly before sleeping, to such an extent that the hairs there were broken off and shortened in a disfiguring manner. Other children will bite their nails, pull the bed cover over the face, will insist on a certain posture, lying on the stomach, or on the bent knees, or display some other preferred position and habit. The mothers know well these little habits, perhaps being responsible for the development of such stereotypias, and are aware of the fact that the child will refuse to sleep if hindered in this peculiarity. Indeed, if this habitual act is made impossible, as by a



Fig. 3.-Curve of depth of sleep in adult (Piesbergen).

newly appointed nurse, falling asleep habitually associated with the stereotypia may be interfered with for awhile until the cause has been found and relieved, or the child has been calmed in some way or weaned from the habit; in short, has forgotten it. The efforts at quieting the child, as for instance, by rocking or by the mother sitting at the bedside, may through indulgence of the attendant supplant the original habit by a new one. A number of these peculiarities are within the normal; in others the readiness of their development, their singularity, degree and persistency may point to a neuropathic basis.

Motor irritation phenomena.-Some motor irritation phenomena may accompany sleep without awakening the child: jerking of the whole body, twitchings of leg or arm, as by an electric shock, various slow movements with the extremities, rolling and tossing, grinding of teeth, etc. Though they may be observed among otherwise healthy children, and particularly under the influence of some febrile disease, these 
phenomena are more frequent among neuropathic individuals. While these motor irritation symptoms have more or less a spasmodic character or are mostly limited to a few muscles, or though coordinate, rather erratic and irregular, other motor manifestations during sleep or at its beginning are more rhythmic, as the jactatio capitis nocturna described by Swoboda and Zappert. ${ }^{4}$ Such rhythmic movements were perhaps at first reproduced consciously in the waking state, as they are frequently to be observed, but under certain exceptional conditions become automatic as subconscious and unconscious habits during sleep. In one of my observations concerning a boy, 14 years old, who was affected for many years with nocturnal headrolling, from which also his father and older brother had suffered, the shaking of the head during sleep was so violent and the left lower jaw so forcibly thrown against the left shoulder that its skin showed a red bruised spot as a mark of the repeated impact. He said that by rolling the head he puts himself to sleep.

Dream acts.-While all the motor disturbances so far mentioned are comparatively simple phenomena, there are more complicated psychomotor processes during sleep which evidence the participation of cerebral centers of higher order, namely, irritative conditions connected with the mental processes of sleep-the dreams. Such dreams are not necessarily always the primary factor, but may be due to some other condition that causes irritation of the nervous system. Children, especially those endowed with an excitable imagination, after playing intensely before retiring, may show such evidence of vivid dreams in which their games play an important part. Some children will laugh even loudly, utter certain sounds or speak short broken off sentences; others will sob. A nervous, spoiled child, 22 months old, when crossed by her attendants at sleeping time would sob incessantly, not only during the period of falling asleep but also during the sleep itself, even for two hours. This sobbing, as a reverberation of an affect whether occurring automatically or under the influence of a dream also happened throughout the afternoon sleep of the girl.

Some babies suck their tongues during sleep, protruding it between the lips, or push the lips forward as in sucking; these movements being during the waking state among the commonest, may during sleep be merely automatic, since they can be seen even in the new-born and in the state of unconsciousness; but perhaps in older nurslings they may, as Zappert ${ }^{5}$ asserts, be transitional forms of dream acts. Dreams in childhood are very frequently the fulfilment of wishes and desires

4. Zappert: Jahrb. f. Kinderh. 62:70, 1905.

5. Zappert: Wien. klin. Rundsch., 1905, p. 720. 
that certainly dominate the psychic life of early age in a much higher degree than in the normal adult.

In these conditions the motor impulses of dream images are transmitted in an activating degree to the cortical psychmotor regions, which in the normal sleep are dormant and inactive. In sleep talking or somniloquy the motor reactions manifest themselves in a variety of peculiarities, anomalies and characters that were the subject of a study by Kreplin, and are in children mostly confined to a low muttering and hardly intelligible talking relating to the experiences of the

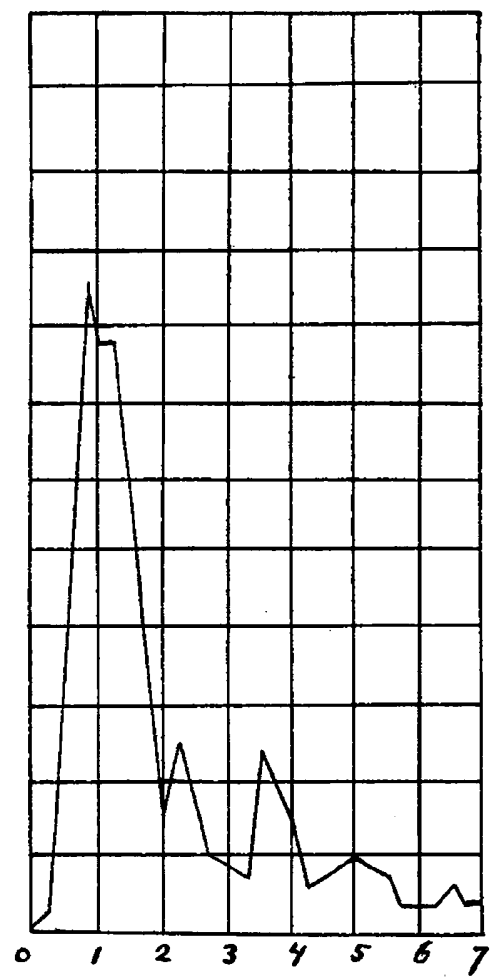

Fig. 4.-Curve after Michelson.

last day. Sometimes the person will also sit up in bed during somniloquy.

Somnambulism. - With sufficient stimulation and irritation of larger cortical and subcortical areas the sleeper may rise from bed, perform complicated acts that have the imprint of a certain deliberation, so different from the motor manifestations that occur without mental processes. They are definite acts, whose motives are dreams. Such dream acts, as exemplified in somnambulism or noctambulism, though rare in the adult and then in connection with hysteria, are fre- 
quent in children. Some authors consider somnambulism in children a neurosis by itself or bring it in some relationship to hysteria or epilepsy, or maintain that it may develop from the basis of a general psychoneuropathic degeneration, without corresponding to these entities; it occasionally occurs also in healthy, though perhaps sensitive, but not actually neuropathic persons. Somnambulism is a pathologic exaggeration of the processes of dreams, "a dream mimically performed and spoken." These dreams, as a rule, have no terrifying character, as is the case with night terrors. The somnambulant child rises and leaves the bed without interruption of his sleep, walks about quietly without any affect and performs complicated acts; he may perambulate through the room, carry objects from place to place, busy himself about his school books, make a light, climb upon furniture or leave the room and move about the house. That children in the somnambulistic state should climb out of windows or undertake really dangerous or marvellous performances is generally declared to be rare. If addressed in a low voice, the child may sometimes answer, but otherwise will be undisturbed in his actions; but intense stimuli, as shaking him up, calling him by his name loudly, pricking, pinching or sprinkling him with cold water, etc., will awaken him. If undisturbed he will return eventually to his bed, continuing his sleep. After awakening in the morning there is complete or almost complete amnesia as to the basic dream and acts.

The somnambule by no means performs his actions purely automatically and mechanically, for they are far too complicated for that and presupose deliberation. The patient acts in his twilight state like a person in the dazed state of intoxication. Though he is sleeping and the associations of the normal sensory of the waking state are not at his disposal, certain domains of his consciousness, limited spheres of his brain, are awake and active; under the dominant dream idea he executes movements that are purposive; he acts his dreams. To a certain extent he is unconscious of external impressions; he may have the eyes open and receive pictures on the retina, which, however, do not penetrate to the sphere of clear selfconsciousness, yet by reflex mechanism may guide him and be the starting point of deliberate and definite movements.

That reality-ideas, thoughts and impressions in connection with experiences and events during day life, especially if accompanied by emotions, desires and intentions, should be carried into acts of the dream consciousness in a half reflective way, or that organic sensations (full bladder) may become a provocative element in somnambulistic actions, is not to be wondered at if we consider their relation to ordinary dreams. The following case may be cited: 
H. B., a 10 year old boy, who, as also his mother, had suffered from enuresis nocturna, would regularly in the night rise and go to the bath room to void urine, without, however, awakening. Lately he walked, as occasionally had occurred before, into another room, pulled out the drawers of his desk and rummaged in his school requisites. His mother found him there, brought him to the toilet room, where he urinated, and led him back into his bed, without his awakening. On another occasion at midnight he rose from bed, walked to the second floor and there passed urine from the porch. After that he suspended himself by both hands from the edge of the porch and was about to let himself down a 15 -foot pole, when a neighbor came up in time to grasp him, still asleep. The boy on previous days had expressed a desire to slide down this pole but was dissuaded. It is noteworthy that loud

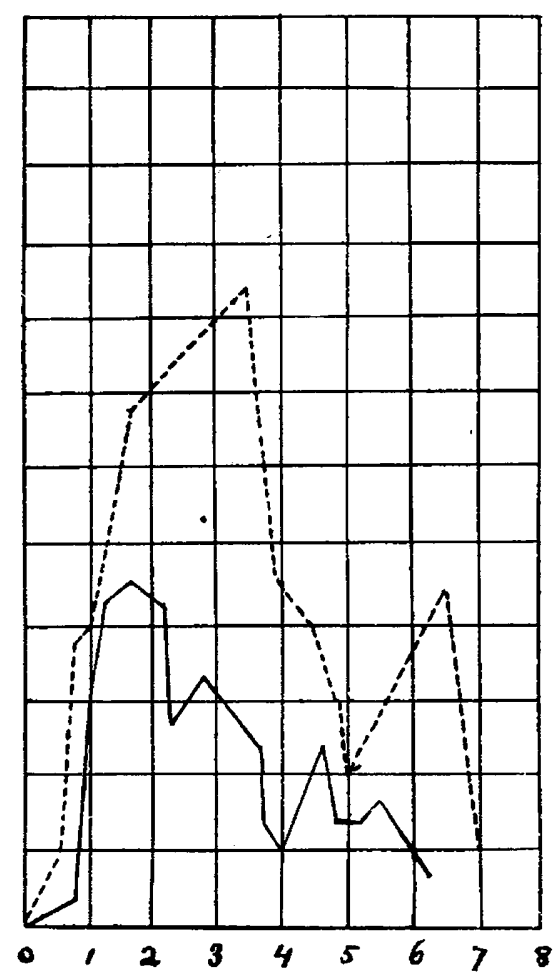

Fig. 5.-Curve after Michelson.

sleep talking is a very regular occurrence with him and that he usually sleeps so profoundly that carrying him about does not awaken him, and arousing him also in the morning is rather difficult.

Children's dreams are more often than in the adult, as mentioned before, simply fulfilments of wishes; thus also in this boy his desire became the motive of a dream act. The following case is a typical representative of the frequent occurrence of a day occupation continuing in dream life and inciting corresponding motor reactions.'

A boy, 8 years old, a bed wetter, for a few weeks would frequently during the night whilst sleeping make movements with his arms, as if in ball play, in which he indulged intensely during the day time, drilling for the 
closing school exercises; he would also utter words referring to this game. In such attacks, for which there existed complete amnesia, he sometimes would leave his bed and have to be brought back.

Quite unusual on account of the early age and the regularity of the somnambulistic acts is the case of a 3 year-old boy; during the previous year he would rise every night without exception whilst sleeping, crawl out of his bed, move about in the half-dark room, mutter unintelligibly or talk sometimes of the dog, the children, his aunt or such things as occupied him in the day time; he also would climb on the bed railing, crawl underneath his bed, grope about and seek something. These attacks would occur one to four times a night. There was no recoliection the next morning. During a recent attack of pertussis the attacks ceased and have not returned.

As a rule if on the part of the attendants no attention is paid to the affection, it soon will disappear, but if in the presence of the child much concern is shown and the disturbance often discussed, it is likely to become aggravated.

That children during sleep irritate their genitals artificially is asserted by some authors. Moll ${ }^{6}$ could, through direct observation, establish the fact that occasionally among even young children, boys as well as girls, such nocturnal acts were practiced, not in the waking state but unconsciously during actual sleep with manual or other irritations. He does not, however, state explicitly whether there was a real masturbation with signs of orgasmus, or merely an affectless playing with the parts during sleep.

Pavor nocturnus.-Among the disturbances of oneirogenic origin, that is, in connection with dreams, without awakening, pavor nocturnus, or night terror, has to be briefly discussed. Not infrequently it alternates or is associated in the same individual with somnambulism, sleeptalking, enuresis, originating from a common neuropathic basis. The dreams, terrible in character, may be provoked by physical discomfort, fever, overloading of the stomach or by carbon dioxid intoxication, resulting from respiratory difficulties, as those due to adenoids, acute or chronic rhinitis, enlarged tonsils, or to retraction of the tongue. Boerner, indeed, could produce certain dreams-incubus-experimentally through carbon dioxid intoxication by covering completely the mouth and nose of the sleeper. We must not, however, overlook the many psychogenic causes, for not infrequently it is nothing else but an actual, disagreeable experience of the previous day, that reappears in the dream and assumes a terrifying character. From patients in whom amnesia is not complete, but only partial, or from the incoherent words uttered during the paroxysm, we may learn that these anxious and agitated states are often due to the return of identical, or at least similar, dream pictures in the same child, of so-called stereotyped dreams. Violent shock, fright and somatic trauma, including surgical operations without anesthesia, may become the psychic stimuli for

6. Moll, A.: Das Sexualleben des Kindes, p. 87. 
this disturbance that assumes the nature of a traumatic neurosis. A very instructive case was that of Professor Gomperz (quoted from Hamburger $^{7}$ ), where a boy immediately after adenectomy without narcosis suffered from pavor every night for some time, manifesting elements of fear in relation to the operation. Henoch in his textbook on diseases of children reports the case of a 4-year-old boy who, after having been frightened by a bee manifested a subsequent night pavor which occurred later repeatedly until he was afraid to enter the bedroom. That an imminent operation may disturb the sleep of older children and create disagreeable dreams is often experienced. These and similar observations dispose of the theory that every pavor nocturnus is due to carbon dioxid intoxication. The more vivid the child's phantasy, the more frightened by others or excited by horrible tales, the more readily in predisposed children will night terror occur, which fact carries a warning to the attendants.

While some authors emphasize the relation of night terror to a neuropathic and psychopathic constitution, or place it side by side with anxiety neuroses, others point to the possibility that occasionally paroxysms may occur also among vivid, not nervous children, especially after hearing terrifying stories or attending exciting moving picture performances, when still under their influence at the time of retiring. We all know adult persons of an entirely healthy nervous system who in their childhood suffered from pavor nocturnus, or even later at least from nightmare and other states of anxiety of minor degree. Of course the more marked the constitutional factor, the psychopathic predisposition, the more insignificant may be the provocation necessary to induce an attack.

Night fears may manifest themselves in various degrees and forms. Horrible dreams, for instance, may cause a mere groaning and sighing, feeble crying or screaming without awakening at all, or, in other cases, cause a wild startling and screaming with the sensorium to a certain degree clouded, or cause full awakening with a feeling of oppression and palpitation of the heart, the sufferer being fully conscious of the cause. The recollection might be entirely absent or very indistinct, as is mostly the case also with our ordinary dreams.

Dream pictures which are psychic phenomena in the sensory cortical region will in children not as readily be corrected as in the adult; the children have not yet sufficiently acquired the faculty of distinguishing vivid dream impressions or dream hallucinations and phantasms, especially if accompanied by affects, from reality. In nightmare which occurs rather in older children than in young ones, the child awakes, and, though remaining somewhat under the influence of the dream

7. Hamburger: Monatschr. f. Kinderh. 13:23, 1914. 
image in the grasp of the reverberating fear emotion, he does not continue to hallucinate but recognizes environment and situation, corrects thus the dream idea rapidly and therefore is quieted more readily than in night terror. Thus we see also in children anxious dreams leading to various degrees and kinds of manifestations; the more violent forms especially in nervous or lively natures. Screaming in fever is not rare even among otherwise healthy children.

Pavor nocturnus, if occurring at long intervals, especially if accompanied by enuresis nocturna and followed by a prolonged dazed condition, should arouse the suspicion of an epileptic basis, as we observe epileptic attacks of this character also in the adult.

That exogenic stimuli, as noises, light, etc., during sleep do influence the content of dream ideas, everybody's self-observation will reveal and has been demonstrated experimentally; the sensory stimulus, however, undergoing various, often fantastic interpretations. For instance, exposure by pushing off the cover, with a feeling of chill, may create the embarrassing dream situation of finding oneself disrobed on the street, or the chilly feeling will be interpreted in the dream as due to a cold wind while preparing for a bath in the open. This is also true as to somatic processes; for example, the peristalsis of intestines, full bladder, distress of heart, etc. Extraneous and somatic factors of a disagreeable sort may thus cause disagreeable dreams with or without awakening. The weight of the incumbent arm and its mechanical pressure on the chest, or sleeping on the abdomen, may provoke some fear dream, as, for instance, the well known incubus, with dyspnea, distressing feeling of oppression, as if an animal were sitting on the chest, or the feeling of being paralyzed and completely helpless. Pain in the limbs from whatever cause may be magnified to an actual laceration by wild animals; a violent neuralgia in the adult may lead to a dream sensation of being stabbed by a dagger, and become the peripheral stimulus for a dream phantasma, in which through associative processes, for instance, thoughts of a murderer, of fight, of danger to life, will ensue. Chronic diseases with organ sensations may lead to the recurrence of the same dream (Wiederholungsträume).

A 12 year old boy patient of Henoch (quoted from Soltmann) suffering from tuberculous spondylitis had night terrors, always connected with the feeling of an animal sitting on his back and pressing him.

A girl of 8, admitted to the Cook County Hospital with mitral affection and severely decompensated heart was for several nights during the last weeks before death found screaming in fear and crouching behind the back rest, whither she had crawled, though otherwise being unable to move on account of orthopnea. Questions asked were answered correctly, but she did not know the cause of her fear nor how she happened to be behind the back rest. 
It is probable, a fearful dream was provoked by oppression in the heart region, creating fear hallucinations; she then acted in a twilight state of half sleep, from which she was easily aroused, but with complete amnesia.

Hypnalgias and allied oneirogenic disturbances.-Of an oneirogenic basis, similar to pavor nocturnus, but without the element of terror, are those peculiar disturbances, as whining, moaning and complaining almost exclusively during the sleep of abdominal pain, or the occurrence of attacks of vomiting or coughing without awakening that yield to simple suggestive therapy (psychotherapy), thus evidencing their psychogenic origin (Hamburger). A case of such oneirogenic gastralgia and vomiting occurring only during sleep and causing awakening was published by me in this journal. ${ }^{8}$ Also in this case the definite disappearance of the nocturnal attacks for which no organic cause could be detected, on a merely suggestive medication with verbal assurance of cure, brought forth into clear view the psychogenic element of this disorder.

Oppenheim has called attention to the relation between certain pains, the so-called hypnalgias and the processes of sleep. A number of his patients, adults, had suffered from cardialgias or neuralgias that aroused them from sleep and persisted only a short time after awakening, appearing again, however, as soon as they yielded to the desire for sleep. In a number of these cases the origin of the disturbance in the view of Oppenheim was probably pain hallucinations, which, like other sensory illusions, are in connection with dreams. In others the manifestations had probably a relationship to the processes of sleep themselves, the altered function of the nervous elements of the brain, its anemia, etc., which, as known, not infrequently create in certain epileptics conditions for nocturnal attacks. Some symptoms, as anxiety, attacks of pain and paresthesias may exacerbate during the night, because the patient gives more attention to his somatic processes; perhaps also due to the abrogation of the influence of the higher nerve centers.

Insomnia.--Insomnia may be transitory or persistent. Though it may have its causes in some organic trouble that has been dealt with before, instances without it occur in childhood, even in infancy, in great numbers and are often very obstinate. The objective examination and further observation will reveal a nervous constitution, the insomnia being only one of several evidences and symptoms of this anomaly. The disturbance may manifest itself at the period of falling asleep, or during the sleep proper, or at both periods. In the first case the children, infants as well as older ones, do not fall asleep as

8. Strauch, A.: Am. J. Dis. Child. 16:165, 1918. 
rapidly as normally after satiation or when put to bed, but lie awake even for hours; the ensuing sleep will be normal, deep and long. No significance will be ascribed to older children' who represent the "morning type" remaining awake late in the evening, fresh and efficient; but it is pathologic, if children who have all signs of weariness, fatigue, sleepiness and desire for rest, cannot find the latter and lie wide awake with open eyes, often anxious and restless. In other cases the individuals fall asleep promptly, but the quality of the ensuing sleep is defective, shallow, readily disturbed and interrupted by slight noises or light, or even without recognizable external causes; there may be shorter or longer periods of wakefulness, during which the children may ask for this or that and disturb the whole household. This is abnormal, since the sleep of healthy children is comparatively sound, and infants are not easily disturbed by the ordinary amusements of their sisters and brothers; and often children who fall asleep on the chair can without awakening be undressed and carried to bed. No doubt, in a number of these cases some minor somatic disturbance may lessen the depth of sleep and thus render them more easily awakened. In still other instances the children merely wake too early in the roorning and find no more sleep; or there may be combinations of these disorders in the various periods of sleep.

Environmental factors.-Appreciating the neuropathic factor in these cases, nevertheless the sleeplessness will not infrequently find its explanation perhaps rather in psychic and pedagogic errors of the environment than in the child itself. Perverted education all too often permits excitement of the child's phantasy by too intense play, by exciting tales or too absorbing reading immediately before going to bed; also allowing too late hours will retard sleep. The relation of kino-performances and child psyche should here be emphasized, especially in nervous, excitable, predisposed individuals, as the former may have untoward effects on the health, creating fears, states of anxiety and vivid, violent dreams, and so sleeplessness. Even films not objectionable from an ethical-moral standpoint may influence most unhygienically the easily aroused imagination, since sentiments and emotions play a great rôle with the child, not to mention sexual stimulation. Fear need not assume a clear idea or image; it may be indefinite. Also agreeable promises may excite a child, as it is a well known fact that the anticipation of a pleasure, for instance on the eve of excursions, pleasure trips, awarding of school honors, etc., will interfere with good sleep.

Intimidation, threatening with the black man, etc., injuries suffered, exciting scenes of the home life, school fears, physical discomfort, may disquiet the child and fill it with anxious dreams and sensations; 
especially with abnormally timid and irritable individuals will such states of fear and various phobias play a great rôle. The young victim may have difficulty in falling asleep or will wake up with a heavy feeling of dread and afterwards spend the night for a period restlessly, controlled by this emotion. The sufferer might then even refuse to go to bed at night out of fearful anticipation of such dream images and phantasms.

A 2 year old, perfectly healthy boy, of a sudden showed great fear when taken to bed one night, clinging to his mother, struggling violently when being laid down, and crying and screaming for half an hour, until he fell asleep from mere exhaustion. Such vehement fear paroxysms occurred thereafter not only at bedtime at night but also at naptime, until the affection finally wore off in a week. Only touching his mother would eventually render him restful; other means, such as sitting of his mother in the room, burning a light, chastisement, etc., were of no avail. After the subsidence of these attacks the child still showed fear for a while even in daylight at finding himself in a room alone. The only explanation for this being afraid of going to bed was frightening dreams following a heavy thanksgiving supper and unusual excitement the night before the fear attacks started.

In other instances children out of fear to sleep alone will permanently ask for this or that or for an adult person to sit at the bedside, but then will distrustfully open their eyes time and again to see whether the person is still present. Instinctive, indefinite fear of darkness may, especially in nervous children, prevent or otherwise disturb sleep.

Sexual factors.-According to Stekel, ${ }^{9}$ children who manifest signs of fear neurosis, have in some way come in contact with the sexual problem; the not understood, not gratified libido, sexual stimulation and suppressed sexual excitement have from subconsciousness or unconsciousness risen into consciousness in the form of anxiety or fear sensations. In his experience exaggerated tenderness, permanent unnatural caressing or negligence on the part of the parents, kissing, hugging, sleeping with the loved person in the same bed, especially of the other sex, but also of the same sex, may call forth prematurely the first erotic instinct and sensation in the child, which is far from being asexual, but, according to Freud, rather "polymorph perverse." Among a number of cases instanced to prove his statement, a boy refused to sleep, because he wanted to watch the undressing of his governess. In his cases the resulting sleep disturbances were promptly cured by complete separation. His observations suggested sexual stimuli by an attending person through unintentional irritations by caressing, kissing and undressing before the child; in other cases, direct sexual traumas, as acts of masturbation. The following case of mutual and solitary masturbation came to my notice the past summer:

9. Stekel: Med. Klin., 1908, p. 621. 
A boy of $4 \frac{1}{2}$ years was observed to practice manual masturbation several times a day and also at night before falling asleep. His $2 \frac{1}{2}$ year old brother, who slept in the same bed, did not fall asleep one night, cried much and fussed until 2 o'clock in the morning. When urged to tell the cause of his behavior, he demonstrated the sexual practices of his older brother on himself and said the latter "had not yet done this to him this night as before."

Though we can not follow Stekel's ultraradicalism in his overemphasizing the sexual element in sleep disturbances in children due to anxiety neurosis, tracing every pavor nocturnus, every chronic sleeplessness to some sexual basis, such possibilities and facts as he instances must be acknowledged to occur, perhaps more frequently than is generally thought. His reported cases carry a strong conviction with them, though I am sure they are rather the exception. In obscure cases we should follow this trend of evidence in our investigation of the etiology of the individual case. That hugging of a beloved mother by the boy or stormy manifestations of affection by the mother may indeed arouse some reactive sensations in the child was brought to my notice again a short time ago by an overindulgent mother who reported that her 4 year old boy when hugging her repeatedly had manifested erection.

That irrational, excessive fondling and nervous behavior of the mother may contribute to sleeplessness, apart from sexual factors, is also shown in the case reported by B. Sachs in his textbook on nervous diseases of children, where the mother used to take the awakened child into her own bed and by caressing and despair over its not sleeping, would excite the child the more, making matters worse and worse, until a trained nurse was taken.

A similar case came to my observation recently.

The nervous mother, wife of a physician, admitted having made herself a slave to her 22 months old daughter. Not only had she to rock the very nervous baby to sleep, but she would, at the slightest whimpering, take her up, fondle and excite her, until the child would rather regularly awake about midnight and cry for as much as two or three hours and tryannize the household; only if rocked would she fall into a very superficial, interrupted slumber. A nurse was employed for two weeks, when the sleep at once became satisfactory, but the former trouble started anew when the mother again took charge of her child.

A 4 year old child of a physician, who sleeps extremely superficially, being disturbed, for instance even by his mother most cautiously entering his room, would, at the age of 2 years, regularly awake during the night, begin to babble and then, apparently without cause, burst forth in a paroxysm of loud, continuous laughter; this would last about one hour and by its violent and forced character had, in the view of the mother, assumed disquieting, wellnigh alarming character, as if foreboding "some mental disturbance." Then, tired out by the paroxysm, the child would cry and shriek for another hour and finally fall asleep from mere exhaustion. The disturbance lasted several months, but has lately occurred only on two occasions during attacks of tonsillitis. 
There can be no doubt that sexual habits in older children actually may banish sleep, the children keeping themselves awake or half awake in order to gratify masturbatory tendencies, as such acts are, especially at night in the solitude of the bed, undisturbed by the possible observation of guardians. Such sleeplessness is intended. Or with the age approaching puberty, psychic-masturbation, that is to say, the indulgence in sexual phantasies, in voluptuous pictures and erotic ideas may be encountered as a cause of delayed sleep. On the other hand, real masturbation may result possibly from simple playing with the genitals, incited by the ennui and tedium of wakefulness itself. Since the act of masturbation often is followed by marked fatigue and exhaustion, as also normal coitus in the adult promotes sleep, it is asserted by good authorities (Heller ${ }^{10}$ ) that psychopathic sleepless children and youths may masturbate not merely for gratification, but also out of intense desire for sleep.

\section{DIFFICULT AWAKENING, INCREASED REQUIREMENTS OF SLEEP}

As falling asleep, so, vice versa, the process of awakening may be difficult. Nervous children are often, even after a long night's rest, still sleeping in the morning, do not want to get up, are peevish if aroused, and dress and breakfast in a sort of half-sleep that only slowly disappears. They are not refreshed, but on the contrary feel tired, are irritable to the extent that insignificant provocations cause excitement. Such children may show in the morning a wilted expression that suggests a nonrefreshing night's rest. Most nervous, but also some nonnervous, children represent the "morning type," of which mention was made in a former paragraph. For them, of course, the too early beginning of school work is not to be recommended even with early retiring; particularly does the shortening of the morning sleep postpone the maximum of efficiency in their day's work. This type is, of course, to be judged in a different way from that in which children, on account of late hours, through wrong education, or on acount of some sleep trouble have not had sufficient sleep in the morning.

An abnormal requirement and profundity of sleep is to be observed in normal children in exhaustion as the result of too great expenditure of energy, and also among cretins and in hypothyroidism. Easily exhausted, nervous children may need an amount of sleep far in excess of the ordinary, and they occasionally manifest a marked desire to sleep during the day, falling asleep at any time, even up to the age of 12 or 14, whereas healthy children from the third or fourth year

10. Heller, Th.: Heilpaedagogik, Ed. 2, Leipzig, 1912, p. 452. 
will object to the afternoon sleep, preferring instead to pursue interestedly their play throughout the day.

In a few extreme cases children reverse day and night in the distribution of their sleeping hours, as in the observation of Baginsky, where a girl of 5 years, suffering from permanent fatigue and discontent, "turned the night into day, and vice versa." No sleep could be obtained in the night, which was passed in singing, playing, eating, etc. ; only during the day would she sleep. A cure was effected in two weeks by change of environment and through strict discipline by an intelligent nurse.

A very profound and fast sleep - be it due to overfatigue or not-is met with in children who suffer from enuresis nocturna. It is noteworthy that the bedwetting mostly takes place in the second or third hour; that is, at the period of deepest sleep. We frequently hear from the parents that loud noises, as the ringing of the doorbell, rapping at the door, etc., do not disturb the child, while the rest of the family are aroused, and it is difficult in such case to awaken the bedwetter in order to have him urinate. In a number of instances the patient, even after shaking vigorously or sprinkling with cold water, would urinate only in a dazed state, in which he would stray confusedly about, not being able to find his bed; yet he may, as I have seen, wet the bed only fifteen or twenty minutes later, having rapidly fallen again into the profoundest sleep. Such children also in the morning are frequently difficult to arouse. A girl of $2 \mathrm{~s} / 2$, who not only suffered from enuresis nocturna, but manifested also other nervous disturbances, as tossing and loud habitual screaming in deepest sleep, was not awakened by violent slapping on the hands, though shrieking was stopped for a while.

The attacks of sleeplike, lethargic states, sometimes observed in epileptics and older hysteric children which occur with or without connection with paroxysms should not be discussed here at length, since they belong to the psychic disturbances of these diseases. The transition from the waking to the hysterical sleeplike state takes place, as a rule, rapidly, in some cases more gradually, and its duration may extend from hours to days and even weeks or months (hysteric pseudodeath). A case in which the epileptic attacks consisted exclusively of sleep with sudden onset was described by Ulrich (quoted from Th. Heller, p. 80).

\section{TREATMENT}

Sleep disturbances in children, as a rule, are easily and readily influenced therapeutically. Before beginning treatment the somatic causes, if any, must, of course, first be made out and alleviated; the possible lack of comfort and hygiene and other disturbing extraneous 
circumstances enumerated before must be considered. The sleep should not be disturbed except for good reasons. Many habits of the nursery, as singing or rocking to sleep, giving unwarrantedly water or milk during the night, too late retiring, taking up the child as soon as he utters the first cry, too much fondling, must be avoided. Irritation, overstimulation of the imagination and provocation of emotions, especially of fear and anxiety, must be avoided, as likewise other errors in education and management.

The more certain it is that fear-affects interfere with sleep, the more must we make efforts to free the victim of them by removing the psychic sources. It would be cruel not to, alleviate dread. It may be necessary to keep the door open, so the child will know that a person is near by, or to keep a light burning low, to be turned down soon, of course, and extinguished finally, until in a few days, as a rule, the child will fall asleep alone in the dark room. Suasion by calming words and other suggestive means should be employed by the mother, as sitting at the child's bedside, placing the hand on its head, stroking, offering a glassful of water, etc. Under these circumstances, however, the possibility must be kept in mind of decreasing the profundity of sleep by a strong light, or of the patient acquiring a new sleep disturbing habit, wanting to be treated always in this way.

Suggestion employed in the waking state has a decided influence on a number of sleep habits and disturbances, in the same manner as on psychogenic disorders manifested during the day.

Many recurring sleep disorders are habits with associations of psychogenic reflexes (pavor, somnambulism, enuresis, etc.). Once the first member of these associations is reproduced, the rest will automatically ensue as a reflex, assuming the type of simple or more complex somatic and psychic processes. The curative mechanism of suggestion lies in the fact that, if the first mental process, the stereotyped provocative conscious or unconscious "memory" is prevented from springing forth, also the supervening psychic reflexes will fail to take place.

An alteration of the psychic life, as, for instance, by change of environment, by transfer to relatives, or especially to a hospital, even a mere threat of it, the separation of the child from the overindulging mother, introduction of a new nurse with disciplining talent, even a mere change of the bedroom will contribute much to influence and abolish entirely those mental complexes that, particularly in children, return in a stereotyped manner before sleep overcomes them. With the former conditions altered as indicated, the child takes entirely new and different ideas into his dream life; and even should the suggestive means fail to prevent entirely the "starting idea," nevertheless it will 
block and inhibit the otherwise ensuing morbid psychoreflectoric complex by diverting the associations in another direction. These extraneous changes, though some of them may seem insignificant to the mind of the adult, will frequently bring about a cure within a few nights of insomnia, pavor nocturnus, enuresis and various other sleep disturbances. This fact also explains the rarity in hospital practice of the occurrence of certain disorders of sleep, as pavor, somnambulism, wakefulness with asking questions, desiring this and that during the night, etc. Promises of reward, threat and punishment, if necessary, will be of aid to the child, as the removing or returning of some favorite plaything. An intelligent, energetic nurse or attendant will work wonders in the home. Also the faradic current is a powerful suggestive means, though rarely necessary.

If in habitual insomnia other therapeutic means are indicated, prolonged, warm, full baths or foot baths, or lukewarm hydropathic packs of body or legs will often be effective. In temporary sleeplessness due to exhausting acute diseases with an urgent indication to induce sleep, as in restlessness of infants from nutritional disturbances with colic pains, or in highly febrile diseases, as typhoid, we should not hesitate to administer drugs until their physiologic effect is established, such as chloralhydrate, bromids, trional, sulfonal or veronal. In the chronic forms of insomnia these drugs are only exceptionally, at most only temporarily, to be prescribed, and then, as soon as possible, discontinued or replaced by pharmacodynamically mild or even indifferent medicines. The latter, as tincture of valerian, are relied on not so much for their physiologic effect as for their suggestive element, masking the principle of psychotherapy in older children. Therefore, they should be given immediately before retiring, accompanied by a strong verbal suggestion of effectiveness, as by the words, "Take the medicine; it will make you sleep" (Hamburger). The assurance of cure is important for the effect of psychotherapy, in order to make a deep impression on the child's mind.

In exceptionally persistent cases, a radical change of the milieu by transfer to a hospital may be necessary. In combating the symptom let us never overlook the treatment of the underlying nervous diathesis by general hygienic and pedagogic measures.

4557 Broadway. 